\title{
Subchronic Oral Dose Toxicity of Freeze-dried Powder of Allomyrina dichotoma Larvae
}

\author{
Jung-Ho Noh ${ }^{1 \dagger}$, Eun-Young Yun ${ }^{2 \dagger}$, Heejin Park', Kyung-Jin Jung ${ }^{1}$, Jae Sam Hwang ${ }^{2}$, \\ Eun Ju Jeong' and Kyoung-Sik Moon ${ }^{1}$ \\ 'Department of Toxicological Evaluation and Research, Korea Institute Toxicology (KIT), Daejeon, Korea \\ ${ }^{2}$ Department of Agricultural Biology, National Academy of Agricultural Science, Suwon, Korea
}

(Received December 15, 2014; Revised March 3, 2015; Accepted March 6, 2015)

\begin{abstract}
The objective of this study was to investigate the toxicological information of freeze-dried powder from Allomyrina dichotoma (A. dichotoma) larvae as a food ingredient. The powder, suspended in distilled water, was administered once daily by oral gavage to four groups of Sprague-Dawley (SD) rats at dose levels of 0 (vehicle control), 250, 850, and $2500 \mathrm{mg} / \mathrm{kg} /$ day. After 13 wks of repeated administration, the standard toxicological parameters such as mortality, clinical signs, body weight, food consumption, ophthalmologic examination, clinical pathology, organ weights and macro/microscopic examination were applied for assessment of general toxicity. In addition, serum IgE and histamine levels were determined to evaluate allergenicity. The freeze-dried powder from A. dichotoma larvae did not produce treatmentrelated changes or findings in any toxicological parameters in either sex of any dosed groups except for slight increases in serum histamine levels at $2500 \mathrm{mg} / \mathrm{kg} /$ day. The changes were considered not to be adverse since the magnitude was minimal. In conclusion, the NOAEL (No Observed Adverse Effect Level) of the freeze-dried powder from A. dichotoma larvae was determined to be $2500 \mathrm{mg} / \mathrm{kg} / \mathrm{day}$ or more in both sexes of SD rats and it is considered a candidate to be edible material.
\end{abstract}

Key words: Allomyrinal dichotoma larvae, 13 wks oral administration, GLP study, Toxicity/safety, Edible insect

\section{INTRODUCTION}

Historically, many species of insects or arthropods such as Coleoptera, Hymenoptera, Orthoptera, and Lepidoptera are important natural resources for human beings (1). They can be consumed as food for humans or animals, and even used for medical purposes $(2,3)$. Today, over 1500 species of insects are known to be consumed for edible material and harvested from nature in 113 countries (4).

Recent studies have shown that many insects have good nutritional content such as crude protein, unsaturated fatty acid, vitamins, mineral elements, and carbohydrate $(5,6)$. For this reason, many researchers have paid increasing

Correspondence to: Kyoung-Sik Moon, Department of Toxicological Evaluation and Research, Korea Institute of Toxicology, Yuseong, Daejeon 305-343, Korea

E-mail: ksmoon@kitox.re.kr

${ }^{\dagger}$ These authors contributed equally to this work.

This is an Open-Access article distributed under the terms of the Creative Commons Attribution Non-Commercial License (http:// creativecommons.org/licenses/by-nc/3.0) which permits unrestricted non-commercial use, distribution, and reproduction in any medium, provided the original work is properly cited. attention to them and examined the nutritional value of such insects and their role in human nutrition $(7,8)$. In Korea, there has been increasing interest in the utility of insects as a new protein source, but no insects, except for Bombyx mori and Oxya chinensis sinuosa, can be produced as food ingredients and sold in a market due to non-registration on the Korean Food Standards Codex.

$A$. dichotoma is a species of rhinoceros beetle found in East Asia including China, Japan and Korea. The larvae have been used as a traditional medicine for the treatment of diabetes (3). Many researchers reported that $A$. dichotoma larvae have various biologic effects including antineoplastic and antihepatotoxic properties (9-11). Based on the previous literature, A. dichotoma larva is considered a valuable source of nutritious food for people. Despite its diverse biological activities, the subchronic oral toxicity of $A$. dichotoma larvae has not been evaluated so far. Thus the present study was designed to support its safety for human use by performing a 13-wks repeated oral toxicity test in SD rats under the GLP regulations of the Organization for Economic Cooperation and Development (OECD) and the Korea Ministry of Food and Drug Safety (MFDS). The protocol of the study was reviewed by the Institutional Animal 
Care and Use Committee (IACUC) of the Korea Institute of Toxicology (KIT), which is fully accredited by the Association for Assessment and Accreditation of Laboratory Animal Care International (AAALAC).

\section{MATERIALS AND METHODS}

Animal and maintenance. Male and female specific pathogen-free Sprague-Dawley rats (Crl:CD(SD)) from Orient Bio Co. (Seongnam, Korea) were approximately 5 wks of age at study start. The animals were acclimatized for 7 days, and then healthy animals were randomly assigned to four groups (vehicle control, 250, 850 and $2500 \mathrm{mg} / \mathrm{kg} /$ day group, 10 animals/sex/group) with additional recovery groups (5 animals/sex/Vehicle control and $2500 \mathrm{mg} / \mathrm{kg} / \mathrm{day}$ group). Rats were housed two animals per cage for the pretreatment and treatment period in a stainless steel wire cage $(255 \mathrm{~W} \times 465 \mathrm{~L} \times 200 \mathrm{H} \mathrm{mm})$. A commercial pellet diet (PMI nutrition International, USA) and sterilized tap water were provided ad libitum. The testing facility provided appropriate environmental conditions $\left(23 \pm 3^{\circ} \mathrm{C}\right.$ room temperature, $12 \mathrm{hr}$ light/dark cycle, $30 \sim 70 \%$ relative humidity, $150 \sim$ 300 lux, 10 20 air ventilation/hr), and cage rack location within the animal room was rotated weekly.

Preparation of the freeze-dried powder of A. dichotoma larvae (fdADL) and analysis. The fdADL, ground to a powder and sterilized, was provided by World Way Co. (Yeongi, Korea). Analysis of proximate composition revealed that $A$. dichotoma larvae contained $38.17 \pm 0.48 \%$ crude protein, $32.72 \pm 0.76 \%$ crude fat, $4.14 \pm 0.04 \%$ crude ash, $22.73 \pm 0.42 \%$ carbohydrate, and $2.25 \pm 0.01 \%$ moisture. The predominant fatty acids in A. dichotoma larvae consist of monounsaturated fatty acid $(57.70 \%)$ such as oleic acid, followed by saturated fatty acids $(36.00 \%)$ and polyunsaturated fatty acids $(6.50 \%)$. Oleic acid $(19.13 \%)$ was the most abundant fatty acid and marker compound followed by palmitic acid (12.52\%), palmitoleic acid (3.71\%) and linoleic acid $(2.08 \%)$ in $100 \mathrm{~g}$ of $A$. dichotoma larvae on a dry weight basis (12).

Formulation of fdADL. The appropriate quantity of fdADL was weighed, and mixed with sterile distilled water (Dai Han Pharm., Korea) for the high dose preparation. The low and middle dose formulations were prepared by diluting the high dose formulation with sterile distilled water. The dose formulations were prepared daily.

Dose levels selection. Based on the results of a previous 4 wks dose toxicity study, the dose of $2500 \mathrm{mg} / \mathrm{kg} /$ day was selected as the high dose for this study and the middle and low doses as 850 and $250 \mathrm{mg} / \mathrm{kg} /$ day, respectively. In addition, sterilized distilled water was administered to the vehicle control group.
Clinical observation, body weight, food consumption and ophthalmologic examination. All animals were clinically observed twice daily except once a day throughout the study period. In addition, detailed clinical observations were conducted once a week during the treatment and recovery period for abnormal behavior and appearance. Individual body weights were measured before dosing on the first day of dosing and once per week thereafter. Final body weight was measured on the day of necropsy. Cage food consumption was recorded once weekly during the treatment and recovery periods. Individual food consumption was calculated as $\mathrm{g} / \mathrm{rat} / \mathrm{day}$. Ophthalmic examination was performed on all animals on week 13.

\section{Clinical pathological examination.}

Hematological analysis: At termination, approximate $1.5 \mathrm{~mL}$ of blood was collected from cauda vena cava of the animals under deep isoflurane anesthesia prior to necropsy. For hematology evaluation, white blood cell (WBC), red blood cell (RBC), hemoglobin (HGB), hematocrit (HCT), mean corpuscular volume (MCV), mean corpuscular hemoglobin (MCH), mean corpuscular hemoglobin concentration (MCHC), platelet (PLT), reticulocyte (RET), differential leucocyte such as neutrophil (NEU), lymphocyte (LYM), eosinophil (EOS), monocyte (MON), and basophil (BAS) were analyzed with ADVIA 2120i hematology analyzer (Siemens, USA). Also, prothrombin time (PT) and Activated partial thromboplastin time (APTT) were analyzed with ACL 9000 coagulation analyzer (Instrumentation Laboratory, Italy).

Clinical chemistry analysis: At termination, approximate $3 \mathrm{~mL}$ of blood was collected from cauda vena cava for their anesthetic states. Whole blood was placed at ambient room temperature for at least $30 \mathrm{~min}$ and centrifuged (3000 $\mathrm{rpm}, 10 \mathrm{~min}$, room temperature) and serum then was separated. For clinical chemistry evaluation, glucose (GLU), blood urea nitrogen (BUN), creatinine (CREA), total protein (TP), albumin (ALB), albumin/globulin ratio (A/G), total cholesterol (TCHO), triglyceride (TG), phospholipid (PL), aspartate aminotransferase (AST), alanine aminotransferase (ALT), alkaline phosphate (ALP), total bilirubin (TBIL), chloride $(\mathrm{Cl})$, creatine phosphokinase $(\mathrm{CK})$, inorganic phosphorus (IP), sodium (Na), potassium (K) and gamma glutamyl transpeptidase (GGT) were measured with Toshiba 200FR NEO chemistry analyzer (Toshiba Co., Japan).

Urinalysis: Before termination, all animals were restricted from diet but not water, and urine were collected overnight (approximately $16 \mathrm{hrs)}$ ) using with metabolic cages. For urinalysis evaluation, volume (VOL), color (COL), clarity (CLA), pH, specific gravity (SG), bilirubin (BIL), protein (PRO), urobilinogen (UBG), nitrite (NIT), glucose (GLU), erythrocyte (ERY) and ketone (KET) were analyzed with Combur 10 TM urine sticks (Roche, Germany) and Cobas U411 urine analyzer (Roche, Germany). Also, microscopic 
examination was conducted for sediments such as epithelial cell, red blood cell and white blood cell.

Terminal procedures. After anesthesizing by isoflurane inhalation and euthanizing by exsanguination on all animals, a full macroscopic examination (abdominal, thoracic and cranial cavities, etc) was performed. Absolute organ weights of brain, pituitary gland, liver, spleen, heart, thymus, salivary gland, prostate, seminal vesicles with coagulation glands), adrenal glands, testes, epididymides, lung, thyroid (with parathyroids), uterus (with cervix), ovaries (with oviduct) and kidneys were calculated, along with the relative organ weights as a percentage of the terminal body weight.

Following a detailed external and internal examination, all tissues were taken from each animal. With the exception of the testes and epididymides, all tissues were preserved in a $10 \%$ neutral buffered formalin solution. The testes and epididymides were fixed in Bouin's fixative for approximately $48 \mathrm{hrs}$ before being transferred to $70 \%$ alcohol. The tissues were processed, embedded in paraffin, sectioned and stained with hematoxylin and eosin (H\&E) under standard histological methods prior to microscopic examination. All preserved tissues from the animals in the vehicle control and high dose group were examined.

Allergy response. At termination, approximate $0.6 \mathrm{~mL}$ of blood was collected from cauda vena cava for their anesthetic states. Whole blood was stored at ambient room temperature for at least $30 \mathrm{~min}$ and centrifuged $(13200 \mathrm{rpm}$, $3 \mathrm{~min}$, room temperature) and then serum was separated. Serum $\operatorname{IgE}$ and histamine levels were measured with $\operatorname{IgE}$ (Rat) ELISA kit (Abnova Corporation, Taiwan) and Histamine ELISA kit (Abnova Corporation, Taiwan). Data analysis and calculation were conducted with SOFTmax Pro Ver. 5.4.1 (Molecular Devices Corp., USA).

Statistical analysis. Variance of homogeneity for different dose groups was examined using the Bartlett's Test.
Homogeneous data was analyzed using the Analysis of Variance (ANOVA) and the significance of inter-group differences was analyzed using Dunnett's Test. Heterogeneous data were analyzed using Kruskal-Wallis Test and the significance of inter-group differences between the control and treated groups was assessed using Dunn's Rank Sum Test.

For comparing control group and recovery group, the data was analyzed for homogeneity for variance using F-test. Homogeneity data was analyzed using T-test and the significant difference between control and recovery group was assessed using Dunnett's Test. Heterogeneous data was analyzed using Kruskal-Wallis Test and significant difference between control and recovery group was assessed using Dunn's Rank Sum Test.

The statistical analyses were performed by comparing the dose groups to the vehicle control group using the Path/Tox system. The results of the comparisons are only indicated when p-values of less than 0.05 or 0.01 were attained.

\section{RESULTS}

Clinical observations, body weight, food consumption, and ophthalmologic examination. There were no treatment-related mortality or clinical signs in either sex of any groups during the study period. Body weight and food consumption also showed no differences between the vehicle control group and the treated groups. In ophthalmologic examination, no abnormal findings were observed in either sex of any group. The body weight and food consumption changes are presented in Fig. 1 and 2, respectively.

Clinical pathological examination. No significant changes in urinalysis parameters were observed in either sex of any groups (data not shown). In addition, there were no treatment-related changes in hematology (Table 1) or clinical chemistry (Table 2) in either sex of any groups.

In hematology, statistically significant decrease in relative lymphocyte count (LYM) was noted in males at 2500
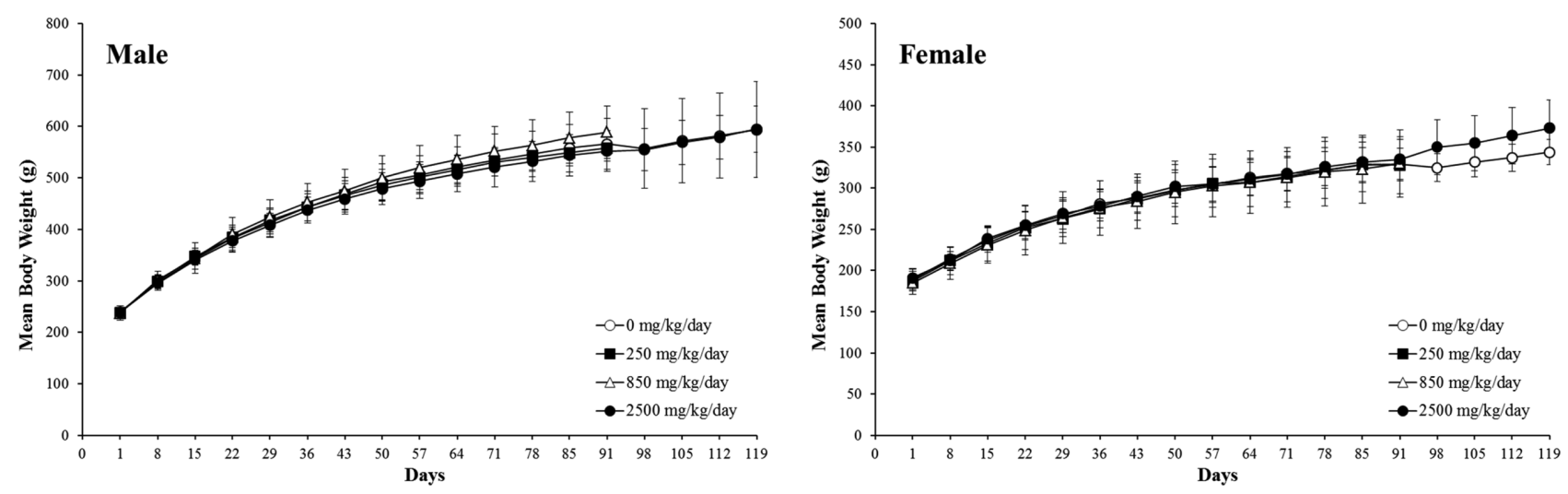

Fig. 1. Mean body weight of male (left) and female (right) SD rats orally administered with fdADL during the study period. 

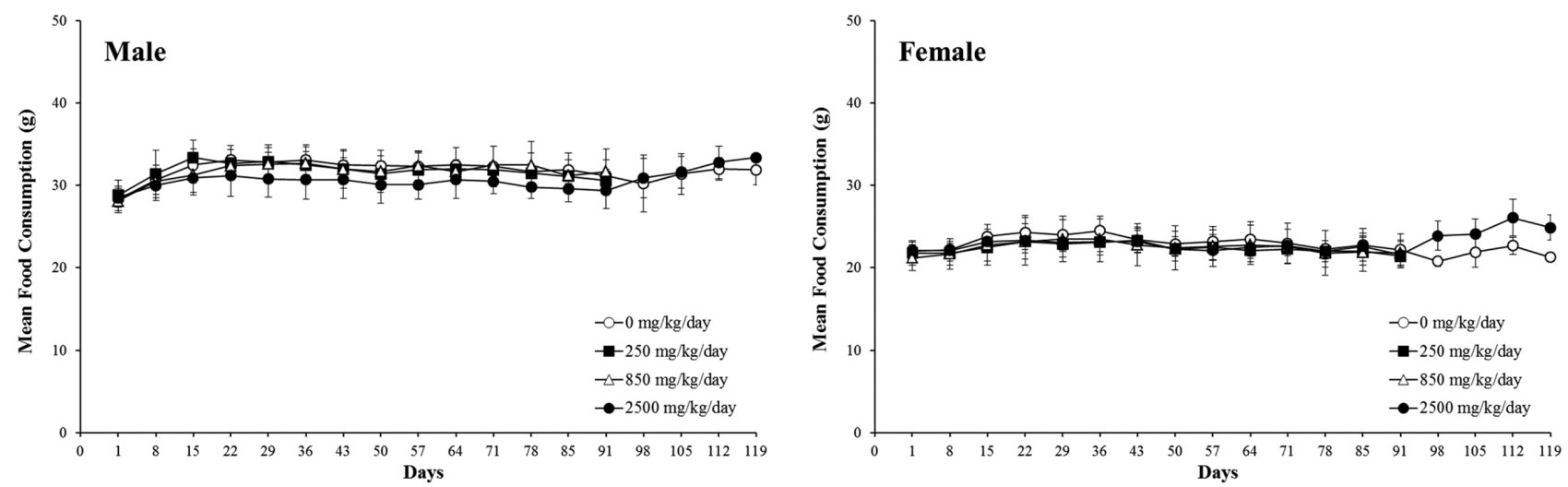

Fig. 2. Mean food consumption of male (left) and female (right) SD rats orally administered with fdADL during the study period.

Table 1. Haematology mean values in male and female SD rats orally administered with fdADL for 13 wks

\begin{tabular}{|c|c|c|c|c|c|c|c|c|}
\hline \multirow{2}{*}{$\begin{array}{c}\text { Sex } \\
\text { Dose } \\
(\mathrm{mg} / \mathrm{kg} / \text { day })\end{array}$} & \multicolumn{4}{|c|}{ Male } & \multicolumn{4}{|c|}{ Female } \\
\hline & 0 & 250 & 850 & 2500 & 0 & 250 & 850 & 2500 \\
\hline No. of animals & 10 & 10 & 10 & 10 & 10 & 10 & 10 & 10 \\
\hline $\mathrm{WBC}\left(\times 10^{3} / \mu \mathrm{L}\right)$ & $10.14 \pm 2.765$ & $8.99 \pm 2.240$ & $9.69 \pm 1.988$ & $8.24 \pm 1.902$ & $6.58 \pm 2.185$ & $5.72 \pm 2.030$ & $6.86 \pm 1.058$ & $6.71 \pm 2.737$ \\
\hline $\mathrm{RBC}\left(\times 10^{6} / \mu \mathrm{L}\right)$ & $8.95 \pm 0.314$ & $8.97 \pm 0.344$ & $9.05 \pm 0.564$ & $8.74 \pm 0.493$ & $8.26 \pm 0.355$ & $8.36 \pm 0.473$ & $8.19 \pm 0.185$ & $8.42 \pm 0.371$ \\
\hline $\mathrm{HGB}(\mathrm{g} / \mathrm{dL})$ & $15.4 \pm 1.13$ & $15.8 \pm 0.54$ & $15.9 \pm 0.98$ & $15.5 \pm 0.71$ & $15.7 \pm 0.64$ & $15.8 \pm 0.51$ & $15.4 \pm 0.52$ & $15.8 \pm 0.70$ \\
\hline HCT (\%) & $47.2 \pm 1.78$ & $47.5 \pm 1.57$ & $49.1 \pm 2.89$ & $46.7 \pm 2.58$ & $46.6 \pm 2.10$ & $47.3 \pm 2.02$ & $46.3 \pm 1.96$ & $47.1 \pm 2.28$ \\
\hline MCV (fL) & $52.8 \pm 1.22$ & $53.0 \pm 1.35$ & $54.3 \pm 1.63$ & $53.4 \pm 1.20$ & $56.4 \pm 1.35$ & $56.6 \pm 2.14$ & $45.5 \pm 2.06$ & $56.0 \pm 1.64$ \\
\hline $\mathrm{MCH}(\mathrm{pg})$ & $17.2 \pm 1.11$ & $17.6 \pm 0.58$ & $17.6 \pm 1.28$ & $17.7 \pm 0.53$ & $19.0 \pm 0.45$ & $18.9 \pm 0.78$ & $18.8 \pm 0.53$ & $18.7 \pm 0.35$ \\
\hline MCHC (g/dL) & $32.6 \pm 2.00$ & $33.2 \pm 0.40$ & $32.4 \pm 1.79$ & $33.2 \pm 0.59$ & $33.7 \pm 0.37$ & $33.4 \pm 0.57$ & $33.3 \pm 0.67$ & $33.4 \pm 0.60$ \\
\hline $\operatorname{PLT}\left(\times 10^{3} / \mu \mathrm{L}\right)$ & $1095 \pm 115.8$ & $1008 \pm 74.5$ & $979 \pm 90.8$ & $1019 \pm 96.4$ & $1139 \pm 123.6$ & $998 \pm 74.0$ & $1051 \pm 95.3$ & $1054 \pm 155.0$ \\
\hline RET (\%) & $1.87 \pm 0.385$ & $1.83 \pm 0.204$ & $1.83 \pm 0.379$ & $1.90 \pm 0.279$ & $2.22 \pm 0.207$ & $1.89 \pm 0.349$ & $2.20 \pm 0.472$ & $1.96 \pm 0.480$ \\
\hline NEU (\%) & $11.8 \pm 3.33$ & $14.3 \pm 5.25$ & $16.4 \pm 11.70$ & $19.3 \pm 7.13$ & $11.2 \pm 2.69$ & $11.4 \pm 4.53$ & $10.5 \pm 3.73$ & $13.3 \pm 4.55$ \\
\hline LYM (\%) & $83.5 \pm 3.58$ & $79.8 \pm 4.46$ & $78.0 \pm 12.08$ & $74.1 \pm 8.50^{*}$ & $82.5 \pm 2.75$ & $82.0 \pm 4.88$ & $84.1 \pm 3.99$ & $81.0 \pm 4.66$ \\
\hline EOS (\%) & $1.1 \pm 0.27$ & $1.3 \pm 0.42$ & $1.2 \pm 0.26$ & $1.4 \pm 0.44$ & $1.4 \pm 0.41$ & $1.2 \pm 0.26$ & $1.3 \pm 0.45$ & $1.6 \pm 0.43$ \\
\hline MON (\%) & $2.6 \pm 0.72$ & $3.1 \pm 0.61$ & $3.2 \pm 1.02$ & $4.0 \pm 1.88$ & $3.7 \pm 1.27$ & $4.1 \pm 1.59$ & $2.9 \pm 1.03$ & $3.0 \pm 1.28$ \\
\hline BAS (\%) & $0.3 \pm 0.11$ & $0.3 \pm 0.11$ & $0.4 \pm 0.12$ & $0.2 \pm 0.13$ & $0.4 \pm 0.15$ & $0.4 \pm 0.13$ & $0.3 \pm 0.11$ & $0.3 \pm 0.08$ \\
\hline LUC (\%) & $0.7 \pm 0.25$ & $1.2 \pm 1.51$ & $0.7 \pm 0.18$ & $1.1 \pm 0.77$ & $0.9 \pm 0.20$ & $0.9 \pm 0.43$ & $0.9 \pm 0.21$ & $0.9 \pm 0.38$ \\
\hline PT (sec) & $13.4 \pm 0.46$ & $13.4 \pm 0.67$ & $13.7 \pm 0.89$ & $13.4 \pm 0.67$ & $13.3 \pm 0.53$ & $13.4 \pm 0.70$ & $13.4 \pm 0.35$ & $13.8 \pm 0.44$ \\
\hline APTT (sec) & $17.9 \pm 1.09$ & $17.8 \pm 1.39$ & $17.4 \pm 1.94$ & $17.0 \pm 1.30$ & $15.3 \pm 2.28$ & $14.6 \pm 1.92$ & $15.1 \pm 1.71$ & $14.5 \pm 1.38$ \\
\hline
\end{tabular}

Values are means \pm S.D.

*: Significant differences from vehicle control group $(p<0.05)$.

$\mathrm{mg} / \mathrm{kg} /$ day on week 13 , but this was considered incidental since there were no microscopic correlates and the value was within normal range (13).

In clinical pathology, a statistically changes in GGT were noted in male and female at $250 \mathrm{mg} / \mathrm{kg} /$ day on week 13 , respectively. These changes were considered incidental since they showed no dose-related pattern and were inconsistent between sexes.

Organ weights, macro and microscopic examination. Absolute organ weight data is presented in Table 3. Relative organ weights data as a percentage of body weight is not presented. There were no treatment-related effects observed between vehicle control and treated groups for any organ weight parameters. In addition, no treatmentrelated macroscopic findings were observed for any treated groups in the study (data not shown).

In microscopic observation, no treatment-related findings were observed in the high dose group. The histopathological findings observed in some tissues at $2500 \mathrm{mg} / \mathrm{kg} /$ day were consistent with common background findings in rats of this age (14). The tissues with high incidence are presented (Table 4).

Allergy response. No significant changes in serum $\operatorname{IgE}$ levels were observed in either sex of any groups. In histamine measurement, the samples of both sexes showed a slight increase along with rise of dosing concentration 
Table 2. Clinical chemistry values in male and female SD rats orally administered with fdADL for 13 wks

\begin{tabular}{|c|c|c|c|c|c|c|c|c|}
\hline \multirow{2}{*}{$\begin{array}{c}\text { Sex } \\
\text { Dose } \\
(\mathrm{mg} / \mathrm{kg} / \text { day })\end{array}$} & \multicolumn{4}{|c|}{ Male } & \multicolumn{4}{|c|}{ Female } \\
\hline & 0 & 250 & 850 & 2500 & 0 & 250 & 850 & 2500 \\
\hline No. of animals & 10 & 10 & 10 & 10 & 10 & 10 & 10 & 10 \\
\hline GLU (mg/dL) & $105.4 \pm 15.59$ & $92.0 \pm 15.08$ & $108.9 \pm 15.90$ & $111.7 \pm 32.70$ & $119.2 \pm 16.34$ & $118.3 \pm 30.87$ & $129.2 \pm 20.75$ & $110.1 \pm 22.98$ \\
\hline BUN (mg/dL) & $13.5 \pm 1.64$ & $15.1 \pm 1.64$ & $14.5 \pm 1.74$ & $14.0 \pm 2.64$ & $17.7 \pm 2.65$ & $17.5 \pm 3.26$ & $17.1 \pm 2.66$ & $18.1 \pm 1.77$ \\
\hline CREA (mg/dL) & $0.46 \pm 0.039$ & $0.49 \pm 0.036$ & $0.46 \pm 0.049$ & $0.51 \pm 0.061$ & $0.58 \pm 0.086$ & $0.60 \pm 0.064$ & $0.60 \pm 0.086$ & $0.60 \pm 0.044$ \\
\hline $\mathrm{TP}$ (g/dL) & $6.98 \pm 0.226$ & $6.89 \pm 0.303$ & $6.96 \pm 0.280$ & $6.78 \pm 0.216$ & $7.83 \pm 0.292$ & $7.87 \pm 0.627$ & $7.79 \pm 0.451$ & $7.66 \pm 0.345$ \\
\hline $\operatorname{ALB}(\mathrm{g} / \mathrm{dL})$ & $4.43 \pm 0.074$ & $4.43 \pm 0.153$ & $4.40 \pm 0.162$ & $4.36 \pm 0.157$ & $5.06 \pm 0.276$ & $5.10 \pm 0.363$ & $5.09 \pm 0.272$ & $4.92 \pm 0.254$ \\
\hline TCHO (mg/dL) & $60.3 \pm 10.45$ & $70.2 \pm 18.41$ & $65.6 \pm 15.51$ & $63.3 \pm 9.01$ & $94.0 \pm 15.10$ & $90.1 \pm 18.82$ & $83.7 \pm 9.99$ & $86.4 \pm 14.99$ \\
\hline TG (mg/dL) & $46.3 \pm 15.61$ & $49.4 \pm 22.48$ & $55.2 \pm 13.96$ & $41.8 \pm 5.28$ & $51.0 \pm 17.41$ & $44.7 \pm 19.65$ & $41.2 \pm 10.73$ & $42.5 \pm 18.87$ \\
\hline PL (mg/dL) & $92 \pm 10.7$ & $104 \pm 24.8$ & $100 \pm 14.9$ & $96 \pm 10.3$ & $174 \pm 21.5$ & $166 \pm 28.7$ & $160 \pm 16.7$ & $158 \pm 18.7$ \\
\hline AST (IU/L) & $122.9 \pm 17.96$ & $149.8 \pm 51.60$ & $119.2 \pm 31.72$ & $126.3 \pm 15.26$ & $128.5 \pm 30.20$ & $121.6 \pm 21.93$ & $111.3 \pm 13.14$ & $143.1 \pm 47.64$ \\
\hline ALT (IU/L) & $31.0 \pm 4.00$ & $45.9 \pm 32.09$ & $31.7 \pm 7.27$ & $28.8 \pm 4.11$ & $41.7 \pm 18.18$ & $32.3 \pm 13.62$ & $30.3 \pm 8.87$ & $52.9 \pm 36.86$ \\
\hline TBIL (mg/dL) & $0.118 \pm 0.0220$ & $0.118 \pm 0.0216$ & $0.116 \pm 0.0112$ & $0.106 \pm 0.0134$ & $0.148 \pm 0.0319$ & $0.140 \pm 0.0219$ & $0.152 \pm 0.0319$ & $0.144 \pm 0.0302$ \\
\hline ALP (IU/L) & $258.4 \pm 53.57$ & $275.9 \pm 55.03$ & $234.8 \pm 32.58$ & $224.1 \pm 38.94$ & $115.7 \pm 33.16$ & $111.9 \pm 27.01$ & $106.4 \pm 25.69$ & $112.9 \pm 27.00$ \\
\hline CK (IU/L) & $621 \pm 117.0$ & $673 \pm 163.0$ & $570 \pm 249.2$ & $586 \pm 165.7$ & $559 \pm 217.9$ & $589 \pm 121.8$ & $517 \pm 158.7$ & $518 \pm 153.2$ \\
\hline GGT (IU/L) & $0.02 \pm 0.076$ & $0.27 \pm 0.272^{*}$ & $0.01 \pm 0.015$ & $0.16 \pm 0.206$ & $0.29 \pm 0.310$ & $0.04 \pm 0.126^{*}$ & $0.09 \pm 0.208$ & $0.23 \pm 0.383$ \\
\hline
\end{tabular}

Values are means \pm S.D.

*: Significant differences from vehicle control group $(p<0.05)$.

Table 3. Absolute organ weights in male and female SD rats orally administered with fdADL for 13 wks

\begin{tabular}{|c|c|c|c|c|c|c|c|c|}
\hline \multirow{2}{*}{$\begin{array}{c}\text { Sex } \\
\begin{array}{c}\text { Dose } \\
(\mathrm{mg} / \mathrm{kg} / \text { day })\end{array}\end{array}$} & \multicolumn{4}{|c|}{ Male } & \multicolumn{4}{|c|}{ Female } \\
\hline & 0 & 250 & 850 & 2500 & 0 & 250 & 850 & 2500 \\
\hline No. of animals & 10 & 10 & 10 & 10 & 10 & 10 & 10 & 10 \\
\hline Brain (g) & $2.16 \pm 0.073$ & $2.12 \pm 0.156$ & $2.18 \pm 0.086$ & $2.10 \pm 0.077$ & $2.00 \pm 0.051$ & $1.98 \pm 0.071$ & $1.96 \pm 0.070$ & $1.97 \pm 0.133$ \\
\hline Pituitary gland (g) & $0.01 \pm 0.002$ & $0.01 \pm 0.002$ & $0.01 \pm 0.002$ & $0.01 \pm 0.001$ & $0.02 \pm 0.007$ & $0.02 \pm 0.004$ & $0.02 \pm 0.004$ & $0.02 \pm 0.004$ \\
\hline Liver (g) & $14.23 \pm 1.148$ & $13.89 \pm 1.131$ & $14.67 \pm 1.686$ & $13.76 \pm 1.499$ & $8.40 \pm 0.847$ & $8.23 \pm 1.259$ & $8.39 \pm 1.101$ & $8.41 \pm 0.568$ \\
\hline Spleen (g) & $0.81 \pm 0.111$ & $0.78 \pm 0.083$ & $0.87 \pm 0.114$ & $0.79 \pm 0.155$ & $0.57 \pm 0.054$ & $0.56 \pm 0.076$ & $0.53 \pm 0.047$ & $0.56 \pm 0.069$ \\
\hline Heart (g) & $1.54 \pm 0.104$ & $1.52 \pm 0.129$ & $1.58 \pm 0.181$ & $1.53 \pm 0.285$ & $1.06 \pm 0.090$ & $1.04 \pm 0.099$ & $1.02 \pm 0.144$ & $1.02 \pm 0.058$ \\
\hline Thymus (g) & $0.41 \pm 0.060$ & $0.38 \pm 0.083$ & $0.40 \pm 0.060$ & $0.35 \pm 0.085$ & $0.30 \pm 0.036$ & $0.31 \pm 0.053$ & $0.33 \pm 0.088$ & $0.33 \pm 0.050$ \\
\hline Salivary glands (g) & $0.77 \pm 0.065$ & $0.78 \pm 0.073$ & $0.83 \pm 0.139$ & $0.73 \pm 0.099$ & $0.50 \pm 0.048$ & $0.49 \pm 0.045$ & $0.48 \pm 0.062$ & $0.51 \pm 0.046$ \\
\hline Prostate (g) & $0.70 \pm 0.122$ & $0.68 \pm 0.090$ & $0.71 \pm 0.174$ & $0.63 \pm 0.126$ & - & - & - & - \\
\hline Kidneys (g) & $3.63 \pm 0.311$ & $3.44 \pm 0.204$ & $3.86 \pm 0.544$ & $3.53 \pm 0.516$ & $2.26 \pm 0.268$ & $2.13 \pm 0.240$ & $2.12 \pm 0.224$ & $2.13 \pm 0.117$ \\
\hline Adrenal glands (g) & $0.06 \pm 0.007$ & $0.06 \pm 0.011$ & $0.06 \pm 0.009$ & $0.06 \pm 0.009$ & $0.08 \pm 0.008$ & $0.07 \pm 0.009$ & $0.07 \pm 0.014$ & $0.08 \pm 0.010$ \\
\hline Testes (g) & $3.41 \pm 0.245$ & $3.48 \pm 0.256$ & $3.37 \pm 0.319$ & $3.24 \pm 0.170$ & - & - & - & - \\
\hline Epididymides (g) & $1.58 \pm 0.098$ & $1.57 \pm 0.128$ & $1.64 \pm 0.166$ & $1.51 \pm 0.097$ & - & - & - & - \\
\hline Lung (g) & $1.76 \pm 0.072$ & $1.69 \pm 0.138$ & $1.68 \pm 0.154$ & $1.78 \pm 0.568$ & $1.38 \pm 0.116$ & $1.34 \pm 0.122$ & $1.31 \pm 0.141$ & $1.40 \pm 0.144$ \\
\hline Thyroid/Parathyroid (g) & $0.03 \pm 0.004$ & $0.03 \pm 0.003$ & $0.03 \pm 0.003$ & $0.03 \pm 0.003$ & $0.02 \pm 0.003$ & $0.02 \pm 0.006$ & $0.02 \pm 0.006$ & $0.02 \pm 0.005$ \\
\hline Seminal vesicle (g) & $2.15 \pm 0.278$ & $2.08 \pm 0.254$ & $2.11 \pm 0.432$ & $2.14 \pm 0.302$ & - & - & - & - \\
\hline Uterus/cervix (g) & - & - & - & - & $0.73 \pm 0.177$ & $0.61 \pm 0.163$ & $0.65 \pm 0.235$ & $0.61 \pm 0.144$ \\
\hline Ovaries/oviduct (g) & - & - & - & - & $0.13 \pm 0.017$ & $0.12 \pm 0.012$ & $0.13 \pm 0.022$ & $0.14 \pm 0.015$ \\
\hline
\end{tabular}

Values are means \pm S.D.

(male: 1.1-1.4 fold, female: 1.1-1.6 fold); however, statistical significance was observed only in females at $2500 \mathrm{mg} /$ $\mathrm{kg}$ /day on week 13 and recovery week 4 (Table 5).

\section{DISCUSSION}

Eating of insect as food has been a common practice in human history all over the world. This food culture dates back to prehistory and is still traditional in many countries $(15,16)$. As the world population continues to grow rapidly, edible insects have received more attention recently, especially in terms of how to develop insects as a sustainable and economic food source in the interest of food security (6). The nutritional value of edible insects has been stated in 
Table 4. Summary incidence microscopic findings in male and female SD rats orally administered with fdADL for 13 wks

\begin{tabular}{|c|c|c|c|c|}
\hline \multirow{2}{*}{$\begin{array}{c}\text { Sex } \\
\text { Dose } \\
(\mathrm{mg} / \mathrm{kg} / \text { day })\end{array}$} & \multicolumn{2}{|c|}{ Male (n) } & \multicolumn{2}{|c|}{ Female (n) } \\
\hline & 0 & 2500 & 0 & 2500 \\
\hline No. of animals & 10 & 10 & 10 & 10 \\
\hline \multicolumn{5}{|l|}{ Kidney } \\
\hline Mineralization & 3 & 1 & 3 & 4 \\
\hline Tubular basophilia & 7 & 5 & 1 & 0 \\
\hline Cystic tubules & 1 & 2 & 0 & 1 \\
\hline \multicolumn{5}{|l|}{ Liver } \\
\hline Infiltration, mononuclear cells & 8 & 10 & 5 & 7 \\
\hline Vacuolated area & 1 & 2 & 2 & 1 \\
\hline \multicolumn{5}{|l|}{ Heart } \\
\hline Cardiomyopathy & 3 & 5 & 0 & 0 \\
\hline \multicolumn{5}{|l|}{ Lung with bronchi } \\
\hline Alveolar macrophage & 2 & 2 & 0 & 0 \\
\hline \multicolumn{5}{|l|}{ Adrenal glands } \\
\hline Cortical vacuolation & 5 & 6 & 0 & 0 \\
\hline \multicolumn{5}{|l|}{ Harderian glands } \\
\hline Pigment & 8 & 10 & 8 & 6 \\
\hline \multicolumn{5}{|l|}{ Stomach } \\
\hline Dilated gland & 2 & 2 & 1 & 1 \\
\hline \multicolumn{5}{|l|}{ Prostate } \\
\hline Infiltration, mononuclear cells & 5 & 6 & - & - \\
\hline
\end{tabular}

many scientific publications. They are known to provide sources of proteins and rich fat comparable to animals (17).

However, safety issue of edible insects is one of the most important considerations when developing the materials into any diet because they can cause severe toxic symptoms or even death in humans after ingestion. Insects may contain harmful materials to human in their bodies in order to protect themselves from natural enemies. Thus, ingestion of insects has potential hazards such as nutritional losses, dyspepsia, tumorigenic metabolites, and allergic reactions (18). It was also reported that eating of Eucheirasocialis (Pieridae) pupae occasionally caused vomiting and headaches in humans, and ingestion of Anaphe spp. caterpillars displayed ataxic syndrome (19-21).

A. dichotoma and its larvae are very popular as one of pet insects in Korea. However its use as food or food additive has been prohibited formally because of lack of toxicological information in humans. Thus, we conducted the 13 wks oral toxicity study of $A$. dichotoma larvae as part of human safety program for toxicological assessment.

In the present study, there were no treatment-related adverse changes or findings in any parameters, when compared to control group. Although some statistically significant differences in the toxicological parameters were observed, these changes were considered to be incidental or in the range of basal area since they were no dose-dependent or inconsistent between the sexes. These results correlate to those of our previous toxicity study of another edible insect, Tenebrio molitor larvae (22). For the results of histamine and IgE levels, it was not considered to be meaningfully involved in the allergy response of $A$. dichotoma larvae although statistical significance on serum histamine level was observed in female group, but not in male group, with $2500 \mathrm{mg} / \mathrm{kg} /$ day group at week 13 and recovery week 4 . The increased level of histamine in $2500 \mathrm{mg} / \mathrm{kg} /$ day dose of female group was not outrageous compared to same dose of male group. Those increases showed less than 2-fold, compare to vehicle control group of this study as well as previously reported data about naïve histamine range in rat bloods $(23,24)$. Moreover, the statistical significance at $2500 \mathrm{mg} /$ $\mathrm{kg}$ /day group in histamine levels could not be considered to imply a biological significance in an allergic manifestation without the accompanied increase of serum IgE levels (25). In fact, overall research articles showed huge differences, from several fold to several hundred fold greater, to demonstrate the correlation between the increase of histamine and IgE levels and allergic response (25-27). Therefore, it was difficult to identify allergic response by using a mere increase rate of histamine levels in the present study.

In conclusion, oral administration of the freeze-dried

Table 5. Serum lgE and histamine levels in male and female SD rats orally administered with fdADL

\begin{tabular}{|c|c|c|c|c|c|}
\hline \multirow{2}{*}{ Sex } & \multirow{2}{*}{$\begin{array}{c}\text { Dose } \\
(\mathrm{mg} / \mathrm{kg} / \text { day })\end{array}$} & \multicolumn{2}{|c|}{$\operatorname{IgE}(\mathrm{ng} / \mathrm{mL})$} & \multicolumn{2}{|c|}{ Histamine (ng/mL) } \\
\hline & & Dosing group & Recovery group & Dosing group & Recovery group \\
\hline No. of animals & & 10 & 5 & 10 & 5 \\
\hline \multirow[t]{4}{*}{ Male } & 0 & $23.9 \pm 11.9$ & $15.1 \pm 12.7$ & $111.9 \pm 26.4$ & $102.1 \pm 31.8$ \\
\hline & 250 & $12.3 \pm 6.6$ & NA & $123.1 \pm 40.4$ & NA \\
\hline & 850 & $18.4 \pm 12.4$ & NA & $142.7 \pm 35.7$ & NA \\
\hline & 2500 & $28.2 \pm 32.5$ & $11.9 \pm 7.7$ & $152.9 \pm 67.6$ & $140.0 \pm 61.3$ \\
\hline \multirow[t]{4}{*}{ Female } & 0 & $12.5 \pm 10.1$ & $10.8 \pm 7.3$ & $85.7 \pm 21.3$ & $99.7 \pm 45.5$ \\
\hline & 250 & $34.1 \pm 56.2$ & NA & $96.2 \pm 23.1$ & NA \\
\hline & 850 & $20.7 \pm 24.0$ & NA & $100.6 \pm 18.4$ & NA \\
\hline & 2500 & $10.3 \pm 6.2$ & $26.1 \pm 23.9$ & $126.2 \pm 43.8^{*}$ & $159.3 \pm 28.0^{*}$ \\
\hline
\end{tabular}

Values are means \pm S.D.

NA: not applicable schedule, ${ }^{*}$ : Significant differences from vehicle control group $(p<0.05)$. 
powder from $A$. dichotoma larvae for 13 wks produced no adverse effects in SD rats given up to $2500 \mathrm{mg} / \mathrm{kg} /$ day; therefore, the NOAEL was established to be $2500 \mathrm{mg} / \mathrm{kg} /$ day or more under this experimental condition.

\section{ACKNOWLEDGEMENTS}

This research was supported by a grant from the Agenda program, Rural Development Administration, and a grant from the Bio-industry Technology Development project, Ministry for Food, Agriculture, Forestry and Fisheries, Republic of Korea.

\section{REFERENCES}

1. Pemberton, R.W. (1999) Insects and other arthropods used as drugs in Korean traditional medicine. J. Ethnopharmacol., 65, 207-216.

2. Miyanoshita, A., Hara, S., Sugiyama, M., Asaoka, A., Taniai, K., Yukuhiro, F. and Yamakawa, M. (1996) Isolation and characterization of a new member of the insect defensin family from a beetle, Allomyrina dichotoma. Biochem. Biophys. Res. Commun., 220, 526-531.

3. Sagisaka, A., Miyanoshita, A., Ishibashi, J. and Yamakawa, M. (2001) Purification, characterization and gene expression of a glycine and proline-rich antibacterial protein family from larvae of a beetle, Allomyrina dichotoma. Insect Mol. Biol., 10, 293-302.

4. MacEvilly, C. (2000) Bugs in the system. Nutr. Bull., 25, 267268.

5. Raubenheimer, D. and Rothman, J.M. (2013) Nutritional ecology of entomophagy in humans and other primates. Annu. Rev. Entomol., 58, 141-160.

6. Alamu, O.T., Amao, A.O., Nwokedi, C.I., Oke, O.A. and Lawa, I.O. (2013) Diversity and nutritional status of edible insects in Nigeria: A review. Int. J. Biodiversity Conserv., 5, 215-222.

7. Banjo, A.D., Lawal, O.A. and Songonuga, E.A. (2006) The nutritional value of fourteen species of edible insects in southwestern Nigeria. Afr. J. Biotechnol., 5, 298-301.

8. Jokthan, G.E., Olugbemi, T.S. and Jolomi, A. (2007) The nutritive value of some microlivestock and their role in human nutrition. Savannah J. Agric., 2, 52-58.

9. Yoshikawa, K., Umetsu, K., Shinzawa, H., Yuasa, I., Maruyama, K., Ohkura, T., Yamashita, K. and Suzuki, T. (1999) Determination of carbohydrate-deficient transferrin separated by lectin affinity chromatography for detecting chronic alcohol abuse. FEBS Lett., 458, 112-116.

10. Kim, D.S., Huh, J. You, G.C., Chae, S.C., Lee, O.S., Lee, H.B., Lee, J.B. and Kim, J.S. (2007) Allomyrina dichotoma larvae extracts protect streptozotocin-induced oxidative cytotoxicity. J. Environ. Toxicol., 22, 349-355.

11. Young, I.S. and Woodside, J.V. (2001) Antioxidants in health and disease. J. Clin. Pathol., 54, 176-186.

12. Youn, K., Kim, J.Y., Yeo, H., Yun, E.Y., Hwang, J.S. and Jun, M. (2012) Fatty acid and volatile oil compositions of allomyrina dichotoma larvae. Prev. Nutr. Food Sci., 17, 310-314.
13. Petterino, C. and Argentino-Storino, A. (2006) Clinical chemistry and haematology historical data in control Sprague-Dawley rats from pre-clinical toxicity studies. Exp. Toxicol. Pathol., 57, 213-219.

14. Mclnnes, E.F. (2012) Background lesions in laboratory animals; a color atlas (1st edition). Elsevier, pp. 17-36.

15. McGrew, W.C., Stanford, C.B. and Bunn, H.T. (2001) The other faunivory: primate insectivory and early human diet in Meat-eating and human evolution (Stanford C.B. and Bunn H.T. Ed.). Oxford Univ. Press, Oxford, pp. 160-178.

16. van Itterbeeck, J. and van Huis, A. (2012) Environmental manipulation for edible insect procurement: a historical perspective. J. Ethnobiol. Ethnomed., 8, 3.

17. Collavo, A., Glew, R.H., Huang, Y.S., Chuang, L.T., Bosse, R. and Paoletti, M.G. (2005) Housekricket smallscale farming in Ecological implications of minilivestock: potential of insects, rodents, frogs and snails. Science Publishers, Enfield, pp. 519544.

18. Gorham, J.R. (1979) Significance for human health of insects in food. Annu. Rev. Entomol., 24, 209-224.

19. Nightingale, K.W. and Ayim, E.N. (1980) Outbreak of botulism in Kenya after ingestion of white ants. Br. Med. J., 281, 1682-1683.

20. Adamolekun, B. (1993) Anaphe venata entomophagy and seasonal ataxic syndrome in southwest Nigeria. Lancet, 341, 629.

21. Anon. (1992) Eucheira socialis - another edible insect which indigenous people are trying to protect from ecological destruction. The Food Insects Newsletter, 5, 4.

22. Han, S.R., Yun, E.Y., Kim, J.Y., Hwang, J.S., Jeong, E.J. and Moon, K.S. (2014) Evaluation of genotoxicity and 28-day oral dose toxicity on freeze-dried powder of tenebrio molitor larvae (Yellow Mealworm). Toxicol. Res., 30, 121-130.

23. Kim, T.H., Kim, E.K., Yoon, H.J., Kim, M.J., Choi, J.E., Oh, Y.M., Shim, S.T., Lim, C.M., Lee, S.D., Kim, W.S., Kim, D.S., Kim, D.W. and Koh, Y. (2003) Role of endogenous histamine on the pathogenesis in the endotoxin-induced acute lung injury. Tuberc. Respir. Dis., 54, 91-103.

24. Bellou, A., Saint-Laudy, J., Knippels, L., Montémont, C., Vauthier, E., Gerard, P., Pellegrom, H., Koerkamp, E.K., Lesesve, J.F., Guéant, J.L., Lambert, H. and Mallié, J.P. (2003) Brown Norway rat ovalbumin-specific immunoglobulin $\mathrm{E}$ antibodies increase the human basophil expression of CD63 marker. Scand. J. Immunol., 57, 271-278.

25. Stone, K.D., Prussin, C. and Metcalfe, D.D. (2010) IgE, Mast Cells, Basophils, and Eosinophils. J. Allergy Clin. Immunol., 125, S73-80.

26. Ji, Y., Sakata, Y., Li, X., Zhang, C., Yang, Q., Xu, M., Wollin, A., Langhans, W. and Tso, P. (2013) Lymphatic diamine oxidase secretion stimulated by fat absorption is linked with histamine release. Am. J. Physiol. Gastrointest. Liver Physiol., 304, 732-740.

27. Yamamoto, Y., Tashiro-Yamaji, J., Sakurai, K., MiyoshiHigashino, M., Nomi, H., Miura-Takeda, S., Okada, M., Yamaguchi, S., Takenaka, H., Kubota, T. and Yoshida, R. (2007) Essential role of monocytes in the in vitro production of IL-4 and nonspecific IgE antibody by peripheral blood lymphocytes from mice sensitized s.c. once with cedar pollen. $J$. Interferon Cytokine Res., 27, 1019-1029. 